Binghamton University

The Open Repository @ Binghamton (The ORB)

$6-2000$

\title{
Workshop to identify critical windows of exposure for children's health: Neurobehavioral work group summary
}

\author{
Jane Adams \\ University of Massachusetts Boston \\ Stan Barone Jr. \\ Anthony LaMantia \\ University of North Carolina at Chapel Hill \\ Rossanne Philen \\ D. C. Rice
}

See next page for additional authors

Follow this and additional works at: https://orb.binghamton.edu/psych_fac

Part of the Health Psychology Commons

\section{Recommended Citation}

Adams, Jane; Barone, Stan Jr.; LaMantia, Anthony; Philen, Rossanne; Rice, D. C.; Spear, Linda; and Susser, Ezra, "Workshop to identify critical windows of exposure for children's health: Neurobehavioral work group summary" (2000). Psychology Faculty Scholarship. 1.

https://orb.binghamton.edu/psych_fac/1

This Article is brought to you for free and open access by the Psychology at The Open Repository @ Binghamton (The ORB). It has been accepted for inclusion in Psychology Faculty Scholarship by an authorized administrator of The Open Repository @ Binghamton (The ORB). For more information, please contact ORB@binghamton.edu. 


\section{Authors}

Jane Adams, Stan Barone Jr., Anthony LaMantia, Rossanne Philen, D. C. Rice, Linda Spear, and Ezra Susser 


\title{
Workshop to Identify Critical Windows of Exposure for Children's Health: Neurobehavioral Work Group Summary
}

\author{
Jane Adams, ${ }^{1}$ Stan Barone Jr., ${ }^{2}$ Anthony LaMantia, ${ }^{3}$ Rossanne Philen, ${ }^{4}$ D.C. Rice, ${ }^{5}$ Linda Spear, ${ }^{6}$ and Ezra Susser ${ }^{7}$ \\ ${ }^{1}$ Department of Psychology, University of Massachusetts-Boston, Boston, Massachusetts, USA; ${ }^{N}$ Neurotoxıcology Divisıon, Cellular and \\ Molecular Toxicology Branch, National Health Effects Environmental Research Laboratory, U.S. Environmental Protection Agency, Research \\ Trıangle Park, North Carolina, USA, ${ }^{3}$ Department of Cell and Molecular Physiology, School of Medicıne, University of North Carolina Chapel \\ Hill, Chapel Hill, North Carolina, USA; ${ }^{4}$ Environmental Hazards Epidemiology Section, National Center for Environmental Heath, Centers for \\ Disease Control and Preventıon, Atlanta, Georgia, USA; ${ }^{5}$ ational Center for Environmental Assessment, U S. Environmental Protectıon \\ Agency, Washıngton, D.C., USA; ${ }^{6}$ Department of Psychology, Center for Developmental Psychobiology, Binghamton University, Binghamton, \\ New York, USA; ${ }^{7}$ Division of Epidemiology, Joseph L Maliman School of Public Health, Columbia University, New York, New York, USA
}

\begin{abstract}
This paper summarizes the deliberations of a work group charged with addressing specific questions ielevant to risk estimation in developmental neurotoxicology We focused on eight questions a) Does it make sense to think about discrete windows of vulnerability in the development of the nervous system? If it does, which time periods are of greatest importance? b) Are there cascades of developmental disorders in the nervo ss system? For example, are there critical points that determine the course of development that can lead to differences in vulnerabilities at later times? c) Can information on critical windows suggest the most susceptible subgroups of children (ie, age groups, 'socioeconomic status, geographic areas, race, etc)? d) What are the gaps in existing data for the nervous system or end points of exposure to it? e) What are the best ways to examıne exposure-response relationships and estımate exposures in vulnerable life stages? f) What other exposures that affect development at certain ages may interact with exposures of concern? gl How well do laboratory anımal data predict human response? h) How can all of this information be used to mprove risk assessment and public health (risk management)? In addressing these questions, we srovide a brief overview of brain development from conception through adolescence and emphasize vulnerability to toxic insult throughout this period Methodological issues focus on major variables that influence exposure or its de ection through disruptions of behavior, neuroanatomy, or neurochernical end ponts Supportive evidence from studies of major neurotoxicants is provided Key words abnormal neurological development, behavioral teratology, behavioral testıng methodology, delayed neurotoxicity, developmental disorders, developmental neurotoxicology, environmental health, neurobiological substrates of function, neuronal plasticity - Environ Heaith Perspect 108isuppl 3) 535-544 (2000)
\end{abstract}

http //ehpnet1 nehs nih gov/docs/2000/suppl-3/535-544adams/abstract htm

To address critical windows of exposure that impact neurological function, it is important to recognize the importance of multiple factors. It is necessary to understand that these windows of exposure are influenced by the mechanism of action of the agent, the target tissue dose of the agent, the developmental tume table of the target tissue, the end point (outcome) of interest, and the age and manner in which that outcome is evaluated [Wilson (1) provides an introduction to these now well-established principles]. Different functions are mediated by different neural substrates, and the timing of developmental events varies with neural substrate. Thus, vulnerability associated with specific time periods of exposure varies with the agent of exposure and the end point of interest. It is also important to recognize the protracted period of development of the nervous system. The architecture and physiology of the brain develop throughout gestation and continue postnatally through adolescent development. Insult at any point during this period may result in aberrant neural structure or function.
Specific aberrant outcomes have been associated with particular windows of vulnerability to specific agents: these developmental windows begin before the formation of the neural plate and end with pubertal neuromaturation. Most neurally active agents appear able to disrupt development at multiple time points across this broad protracted period. Depending on the timing of exposure, the end points affected may also vary. For a single end point, however, there is often a period of greatest vulnerability as defined by the production of the outcome at a lower level of exposure to the agent. The outcome itself may be expressed only after (or perhaps at) a particular developmental stage and may be revealed only under certain conditions of measurement. Natural conditions such is aging or experimental conditions such as social, pharmacological, or other environmental challenges may be necessary to reved the deficit.

Inherent in the brain's protracted period of development, however, is also the phenomenon of neuroplasticity and the nervous system's consequent potentral for compensation after insult. Although it is important to understand the role that compensatory mechanisms may play in the manifestation of the effects of devclopmental exposures, our view is that the detection of adverse outcomes at any age is a primary goal of screening and risk assessment, and transient as well as permanent adverse effects need to be guarded against. For this reason, we view an examination of neuroplasticity as beyond the scope of this review.

The protracted period of development and the protracted period over which outcomes must be measured to adequately assess dysfunction of the nervous system complicate the establishment of causal relationships in epidemiological studies of developmental toxicty. Certain aberrations in development are directly caused by exposure-based events (e.g., abnormalities in the development of the hypothalamic-pituitary axis), whereas others may represent downstream consequences of exposure (e.g., reduced body weight, increased vulnerability to birth trauma, alcered responses to stress, and decrements in learning and memory). It is important to distinguish between primary developmental aberrations caused by toxic exposure and downstream effects. It is also important to recognize that although there are numerous outcomes of developmental neurotoxicity, their expression (and measurement) is limited to a finıte set of readily observable outcomes. Such abnormalities may include specific aberrations resulting

This article is based on a presentation at the Workshop to Identify Critical Windows of Exposure for Children's Health held 14-16 September 1999 in Richmond, Virginia

Address correspondence to $J$ Adams, University of Massachusetts-Boston, 100 Mornssey Blvd. Boston. MA 02125 USA Telephone (617) 287-6346 Fax (617) $287-6336$ E-mail jane adams@umb edu

We thank $C$ Kimmel, $P$ Mendola, $S$ Selevan, $S$ McMaster, and L White

This manuscript was reviewed and approved for publication by the NHEERL, US Environmental Protection Agency Mention of trade names or commercial products does not constitute endorsement or recommendation for use The opimions expressed by the authors are not to be misconstrued as policy of the US EPA

Recerved 10 January 2000 , accepted 8 March 2000 
from diverse events, potentially emerging at different times. Just as different mechanısms may lead to grossly simular anatomical expression (e.g., gross examination may not distinguish missing tissue due to agenesis vs. overactive apoptosis), different mechanisms and primary neural abnormalities may lead to similar behavioral manifestations (e.g., neurochemical dysfunction due to altered neurotransmitter production or to altered receptor dynamics may similarly alter behavior). Functional alterations serve as apical tests of underlying primary neuroanatomical, neurophysiological, and/or neurochemical abnormalities resulting from exposure.

The ease of detecting the primary underlying abnormalities varies with the resolution of the technology. As a resulc, behavioral disruptions may sometimes be detected in animals or in children whose neuropathology remains unidentified by standard means. The failure to consistently identify neuroanatomical abnormalities in animals with behavioral dysfunction has led to some investigators' conceptualizations of robust behavioral effects subtle. Although the extent to which such effects may defy detecrion has merited their being labeled subtle, the term should not be used to imply milder. Ambiguity is often present in the interpretation of certain so-called subtle behavioral effects as potentially mild when seen in rodents; the ambiguity is easily resolved in human manifestations. For example, identification of gross neuropathology has not been consistently possible in studies of mentally retarded children (2); however, mental retardation would not be considered a mild effect when produced by a toxic exposure. Unfortunately, however, the connotation of the "subtle" terminology has, in part, led some to misinterpret the model of severity of outcome, where frank malformation is at one end of a continuum and behavioral dysfunction at the other. This has sometimes led to the incorrect conceptualization of detectable anatomical changes in any organ system as being more severe outcomes of exposure than behavioral impairments, when dysfunction was not accompanied by gross pathology of the brain. For many compounds (ethanol, retinoic acids, and valproic acid), the nature of the dose-response relationships suggests that higher doses are associated with outcomes such as major malformations, whereas lower doses produce behavioral change in the absence of grossly detectable neuropathology. However, many (perhaps most) environmental developmental toxicants that influence behavioral, hormonal, or growth outcomes do so in the absence of malformation induction at higher doses where maternal toxicity and/or fetal death may occur [e.g., lead, mercury, polychlorinated biphenyls (PCBs), amphetamine, and cocaine]. Thus, in the context of screening, behavioral alteration may sometimes be the only marker for risk assessment. Research has clearly linked behavioral dysfunction with ultrastructural or molecular abnormalities in brain development; however, these end points are not part of current screening approaches.

In this paper, we interweave empirical evidence for our opening perspective with our responses to the eight specific questions provided as workshop directives. 1) Does it make sense to think about discrete windows of vulnerability in the development of the nervous system? If it does, which time periods are of greatest importance? 2) Are there cascades of developmental disorders in the nervous system? For example, are there critical points that determine the course of development, which can lead to differences in vulnerabilities at later times? 3) Can information on critical windows suggest the most susceptible subgroups of children (i.e., age groups, socioeconomic status, geographic areas, race, etc.)? 4) What are the gaps in existıng data for the nervous system or end points of exposure to it? 5) What are the best ways to examine exposure-response relationships and estimate exposures in vulnerable life stages? 6) What orher exposures that affect development at certain ages may interact with exposures of concern? 7) How well do laboratory animal data predict human response? 8) How can all of this information be used to improve risk assessment and public health (risk management)?

\section{Discrete Windows of Vulnerability in Neural Development}

The first question considered at the workshop was as follows: Does it make sense to think about discrete windows of vulnerabılity in the development of the nervous system? If it does, which time periods are of greatest importance? Empirical evidence substantiates multiple periods of vulnerabil1ty to toxic insult in the developing nervous system spanning from early gestation to adolescence in humans and experimental animal models (3-5). Toxic insults during this protracted period can result in diverse outcomes ranging from structural abnormalities emergent during early embryogenesıs that may be incompatıble with pre- or postnatal survival, to ultrastructural or molecular abnormalities potentially emergent at any developmental point and associated with functional deficits. Wilson (l) originally described the manifestations of abnormal development as represented by four main categories: death, malformation, growth retardation, and functional deficit. He also put forth as a principle of teratology that "manifestations of deviant development increase in frequency and degree as dosage increases from the no-effect to the totally lethal level." Some developmental toxicants that are capable of disruption of morphogenesis through molecular mechanisms demonstrate this conventional neuroteratogenic profile whereby all outcomes on the continuum of abnormal development may be induced at different stages and varying exposures [e.g., tetinoids $(6,7)$ ]. However, other developmental tox1cants that act through the disruption of other morphogenetic signaling or neurotransmitter systems appear not to produce gross malformations at doses below those capable of producing maternal toxicity. These agents produce robust effects that are less readily detectable and less easily associated with narrow periods of heightened vulnerability than is the case when gross malformations are produced. Nevertheless, the consequences may be equally robust. Thus, multiple neuroanatomical, molecular, and behavioral end points are necessary to assess the effects of insult to the developing nervous system. The windows of greatest vulnerability to disruption of the neural mediators of these various outcomes vary with the agent of exposure, dose of the agent, and its associated mechanism of action, as well as the age at assessment and other characteristics of the assessment methodology. Thus, it makes sense to think about discrete windows of vulnerability only when we recognize the importance of other variables. Empirical evidence demonstrates that exposure during finite windows of exposure produces quantitatively and qualtatively different outcomes. This has been demonstrated not only in relation to mult1ple outcomes of prenatal exposure but also after exposure during different windows of postnatal development in rodents [e.g., organotins $(8-10)]$. Thus, it makes sense to think about windows of vulnerability only in the context of a specific end point or set of end points; otherwise, defining the most vulnerable period requires that outcomes be evaluated according to a severity index. In the case of hazard identification for chemicals in which limited data exist on mechanism or mode of action or little information is available in the literature examining critical windows of exposure and developmental effects, it becomes hard to assume what the critical window of exposure may be. In these cases the default assumption could be that the entire period of neural development may be vulnerable (i.e., beginning before neurulation and ending after puberty). We first consider the range of end points necessary to assess potential developmental effects of toxicity. We then address the windows of greatest vulnerability for effects on selected outcomes. Finally, we discuss assessment 
cliaracteristics that appear relevant to the derection of toxic insults.

\section{Necessity of Multiple End Points to Detect Potential Developmental Neurotoxicity}

Because developmental neurotoxicity can be expressed through anatomical, physiologic.t, neurochemical and/or behavıoral end points, assessments of multiple end points are necessary. Because there are a multitude of measures for the study of structural or functional effects of exposure, it is most elficient to focus on more mainstream measures incorporated into screening studies [reviewed by Meyer (11), Kimmel (12), Adams (1.3), and the U.S. Environmental Protection Agency (EPA) (14)]. We compare screening methods with techniques t at have emerged as the most valuable from a range of scientific studies conducted in the last decade. Studies in developmental toxicology may examine andromical and gross physical end points along with behavioral ones. Although behavioral measures themselves have been limited in testing batteries, they have nevertheless often been more extensive than corresponding examınations of neuroanatomical or neurochemical end points. In the context of screening studies conducted in rodents, the need for a battery of tests to measure functioning in diverse behavioral systems has long been recognized $(15,10)$. The development of behavioral testing batteries has received more regulatory attention than has the need for a sophisticated battery approach that includes the examination of current neuroc natomical or neurochemical/molecular end points. More extensive measurement of neural structures and neurochemical systems must be incorporared with a more sensitive modernday behavioral screening battery. The incluion of neurochemical assessments during critical periods of maturation and in adults with prior developmental exposure may be warranted in cases where chemicals affect 'pecific neurotransmitter systems in either in vitro assays or in the adult nervous system after exposure. This is predicated on the qualitatively different role as neurotrophic factors that neurotransmitter systems play during development [reviewed by Buznikov et al. (17) and Rice and Barone (13)] .

Behavioral test batteries generally contain measures of viability, growth, and physical developmental landmarks along with measures of motor development, sensory functoning, activity levels, reactivity, and learning and memory. The rationale for this screening battery approach emphasizes that different agents and exposures at different times to the same agents result in effects on different systems measured within the battery
(19,20). Because most regulatory approaches to screening have incorporated relatively long exposure windows, assessing a multitude of potentially vulnerable systems is paramount. In the context of windows of vulnerability, we must always recognize that the window of greatest vulnerability may vary with the end point under examination. If the relevant end point is not examined, the effects will not be detected. Likewise, if the relevant end point is inadequately assessed, effects may not be evident.

Use of the batrery approach in the last decade has reinforced the need to assess the categories of functioning but has challenged the value of or suggested more valuable measures within each category. Also, routine incorporation of other methods in research studies has demonstrated the value of examining other end points.

\section{Distinctive Neural Systems Have Different Periods of Vulnerability}

Different areas of the brain mediate different types of information processing and are related to different kinds of neural function. Whereas all neural processing involves multiple neural centers and major pathways connecting specific structures, it is heuristic to recognize certain critical sites. Rice and Barone (18) discuss the following areas in their background paper: prefrontal structures for working memory and executive functions; medial temporal lobe structures for certain aspects of learning and memory; and brainstem structures for regulation of arousal, sleep-wake cycles, and multıple autonomic nervous system functions. Each area has its own protracted period during which neurogenesis, migration, specification, elaboration of neurons, apoptosis, and internal synaptic connectivity as well as establishment of input/output circuits take place. The background paper by Rice and Barone ( 18 ) and a review by Holson (21) provide information on specific time periods for different brain areas. Jensen and Catalano (22) provide an overview of nervous system morphogenesis; their overview is a primary source for this limited extraction. In light of brain area and circuit-dependent differences in the tuming of developmental events, it is not surprising that behaviors mediated by different brain systems would be disrupted by insults at different times during development. It is also not surprising that disruption of some embryonic developmental events results in gross malformations as a consequence, whereas more commonly, developmental insults result in cytoarchitectural or molecular alterations. Therefore, the particular agent and end point under investigation will determine the temporal window identified as most vulnerable to insult.
Neural Vulnerability Spans from Early in Gestation through Adolescence

A series of developmental events appear to define perrods of greatest vulnerability to insult. These developmental events occur at different times for different neural structures and circuits. Thus, there is no simple categorization of morphogenesis of the central nervous system into discrete temporal nonoverlapping categories. Therefore, our discussion of vulnerable windows is kept very broad, instead emphasizing the protracted, interactive, and temporally overlapping nature of stages and major morphogenetic events. Our discussion incorporates the embryonic, fetal, and early postnatal periods of brain development, then focuses on adolescent brain development. We provide supportive evidence for disruption of different processes and events for selected agents.

Vulnerability before induction of the neural plate through neural tube closure and formation of the rbombencephalon. The period in human pregnancy that occurs before the induction of the neural plate is before day 18 postconception. In the rat, this period is before day 9. Toxic disruption of developmental events prior to neural induction has been demonstrated after early exposures to diabetic conditıons, retinoic acid, methylnıtrosourea, and clomiphene [reviewed by Bennett and Finjell (23)]. Such exposures resulted in an increased incidence of neural tube defects and certain other malformations despite exposure before neurulation.

Better understood, however, are the effects of toxic agents during the neurulation process itself (human: approximately days 18-28, rat: approximately days 9-12) primarily in regard to insults that result in death or neural tube defects qualifying as major malformations $(6,22,23)$. Such malformations include anencephaly, spina bifida, encephaloceles, and myelomeningoceles. Classic teratogens include retinoic acid, arsenic, and valproic acid as well as hypertherma [retinoic acid was reviewed by Adams (6) and Adams and Holson (7); other agents were reviewed by Bennett and Finnell (23)]. These agents appear to evoke diverse mechanisms that result in neural tube defects as a final common, categorically similar outcome.

Abnormalities other than the classic malformations can also result from exposures before and around neural tube closure, around the time of rhombomere formation $(23,24)$. Effects on hindbrain structures such as brainstem and cranial nerve nuclei are clearly demonstrated by exposures to valprorc acid and thalidomide (24,25). Effects on bratnstem, cranial nerve nuclei, and cerebellar structures have also been shown after exposures to retinoic acids (7,26-29). Early on, these agents were associated with behavioral 
deficits in the absence of identified neuropathology [retinoic acid was reviewed by Adams ( 6 ) and Adams and Holson ( 7 ); valproic acid was reviewed by Dansky and Finnell (30), Finnell and Dansky (3l), and Hansen and Holson (32)].

Brain development after neural tube closure: vulnerability in multiple processes and events that are interactive and overlapping. Morphogenesis of the nervous system begins with the induction of the neural plate and continues into postnatal development. Although neurogenesis was originally believed to end during the early postnatal years in humans, it is now recognized to be present to a limited degree throughout life [reviewed by Kempermann and Gage (33)]. Nevertheless, extensive neurogenesis is limited to early development in humans, and in rats appears to encompass gestational days 11-22, except the hippocampal and cerebellar microneurons, which develop postnatally in the rat (21). During early stages, the segmented brain first develops into a trivesicular organ that includes the rhombencephalon, mesencephalon, and prosencephalon. The migration of neurons eventually results in the formation of all structures of the brain. During this extended period of morphogenesis, multiple processes occur that are necessary for the development of neuronal and glial elements and their complex circuitry. Intra- and intercellular interactions involving multiple trophic agents constantly act to create, shape, and then remodel the brain and nervous system. Clearly, descriptions of these developmental events are beyond the scope of this paper. A detailed overview of the processes and events of brain development can be found in Jensen and Catalano (22). Rice and Barone (18) discuss a temporal characterization of processes such as proliferation, migration, synaptogenesis, gliogenesis and myelinogenesis, and apoptosis in relation to particular brain areas. Barone (34) and Barone et al. (35) provide more extensive reviews of processes, signaling, and trophic molecules involved in development. Of importance here is the fact that toxic interference with these fundamental developmental processes and multiple signaling and trophic agents has been well documented to result not just in malformations, but more commonly in cytoarchitectural and molecular alterations that are expressed as behavioral dysfunction. For environmental agents associated with long-term exposure patterns, behavioral, neuronal, or molecular effects have been associated with a greater number of agents than have the early developmental malformations associated with classic teratogens. Thus, environmentally relevant levels of lead, mercury, pesticides, PCBs, and many other agents pose a greater threat to perturbation of developmental processes like synaptogenesis than to expressions of insult through gross malformations. Herein lies the dilemma: qualitative histological examination of Nisslstained sections of the brain (as required by some guidelines) does not adequately assess neuroanatomical and neurochemical characteristics with the resolution necessary to detect these changes. Morphometric analysis, at least on a regional level during brain development, can provide some estimates of delays in synaptogenesis or persistent alterations in synaptogenesis and/or dendritic elaboration [reviewed by Barone et al. (35)]. Likewise, some methods of evaluating alterations in behavior or other neurological functions may be inadequate to detect many subtle effects. This could be critical for child health protection if subtle effects in animals are missed or in some instances dismissed because they are only observed in the highest dose group under study and are possibly confounded with indices of maternal toxicity. Let us consider lead and methyl mercury toxicity to illustrate the relationship among neuroanatomical, neurochemical, and behavioral effects. These agents were selected because of their historical prominence, their relevance to regulatory actions, and the extent of available data. They allow discussion not only of outcomes but also of primary substrates that are affected, and also illustrate some age-dependent vulnerabilities. Broader discussion can be found in Rice and Barone (18), Dietrich (36), and Bellinger and Dietrich (37).

Lead. Lead is a good example of a developmental toxicant whereby under conditions of long-term, low-Jevel exposure, behavioral disruption is the primary outcome. Bellinger and Dietrich (37), Dietrich et al. $(38)$, and Rice $(39,40)$ published excellent reviews on this subject. Exposures that are mostly postnatal and often restricted to infancy (substantiated in these reviews) as well as prenatal exposures (4I) have been associated with the production of general intellectual deficits as well as deficits in specific sensory and cognitive abilities. The fetuses and children appear more susceptible to these effects than adults. Effects on gross brain structure have not been evident in studies directed at understanding underlying neuroparhology associated with low-level lead exposure. Instead, the effects most consistently noted are those on synaptogenesis and dendritic arborization $(42-46)$, in vivo physiological examinations of synaptic plasticity $(47-49)$, and decrements in myelination $(50,51)$. Changes in glutamate and $\gamma$-aminobutyric acid synthesis and release $(52,53)$ and the glutamate $N$-methyl-I)aspartate (NMDA) receptor levels and binding affinities have also been reported in association with low-level lead exposure
(54). Direct inhibitory actions of lead on NMDA receptors in the hippocampus have also been associated with and used to explain synaptic changes as well as cognitive impairments in lead-exposed rodents and children (54). Thus, lead exposure can disrupt developmental events that begin prenatally but continue during early childhood, and can do so at multiple points during that interval.

Methyl mercury. Because of the poisoning at Minamata Bay, Japan, in the mid1950 s, the results of high- as well as lower level exposures to methyl mercury have received a great deal of research attention. As was the case for lead, the fetus and child are more susceptible to methyl mercury toxicity than adults [reviewed by Chang et al. (55) and Burbacher et al. (56)]. Burbacher et al. (56) examined the comparative characteristics of methyl mercury exposure to developing humans, macaque monkeys, and rodents. They showed clear dose-response effects for behavioral as well as neuropathological end points that were quite consistent across species. Effects were examined across low $(<3$ ppm), moderate (3-11 ppm), and high (12-20 ppm) doses defined by brain tissue content. Dose-related effects on behavioral outcomes were manifested as cognitive deficits or delayed development at low doses, cognitive and sensory electrophysiological effects at moderate doses, and severe sensory (blindness), cognitive, and motor (spasticity) abnormalities as well as seizures at high doses. Neuropathological effects in rodents exposed across these dose ranges included cellular loss and decreased brain size at low doses, decreased brain size, cortical and cerebellar defects, and reduced myelin at moderate doses, and these same effects plus effects on additional brain structures at high doses. More recent work has identified disruptions in neuronal proliferation and migration, dysmyelination, hypoplasia of the corpus callosum, and hydrocephalus in association with high doses; lower level exposures have been associated with migration and cytoarchitectural defects (57). Mediation of toxic effects on neural development may involve alterations in cell adhesion molecules and cytoskeletal proteins (56) and neurotrophic factor signaling (58-60).

Vulnerability during the adolescent period of development. In addition to the dramatic neuroendocrine and physical changes associated with adolescence, from even the limited amount of literature available, it is clear that the brain of the adolescent also undergoes striking transformations. Several brain regions undergo prominent remodeling during adolescence across a variety of species. These regions include the prefrontal cortex and other forebrain regions to which mesolimbic dopaminergic terminais 
project. In addition to an adolescentassociated decline in the volume of the prefrontal corcex [humans (61); rats (62)], there is also substantial synapse elimination of pre$s u m e d$ glutaminergic excitatory input in motor cortex (63) while dopaminergic input to the prefrontal cortex increases during adolescence to reach levels higher than that seen earlier or later in life [reviewed by Lewis $(64)]$. Estimates of basal synthesis and turnover of dopamine decline in prefrontal cortex dur'ng adolescence in rats, which contrasts with the increase in these measures reported in the nucleus accumbens and striatal dopamine terminal regions of adolescent rats $(65,66)$. Maturational events have also been reported in a vartety of other areas including the hippocampus [humans, (67); rodents, (68), and hypothalamus (69)].

These data suggest that the adolescent period of brain development should be a time of particular vulnerability to insult. However, there has been surprisingly little investigation in either humans or animals of the vulnerability of adolescent brain to developmental per1 urbation. Some studies in experimental animals huve begun to address this data gap. Salimov er al. (70) reported that ethanol con'umption by adolescent alcohol-preferring rats altered later behavioral responsiveness to rovelty and a swim stressor. Golıszek et al. (71) reported that long-term stress of rats from 4 to 10 weeks of age [a period that the authors defined as prepubertal but which should span the entire pubertal period $(72,73)]$ permanently altered the animal's ability to release adrenocorticotropic hormone, even when subjected to considerable stress; males were particularly vulnerable in this regard. These few examples clearly demonstrate that explorations of the consequences of insults during adolescent brain development remain unexplored territory that should be quite fertile for future research.

The detection of the effects of developmental toxicity can be optimized by attention to specific assessment characteristics. Studies in developmental toxicity have shown not only a protracted period of vulnerability but also a protracted period over which the consequences are expressed. Whereas one can simply say, for example, that the behavior or neural system must first have developed before its integrity of function can be examined, the issue is far more complex. Among issues of imporiance are a) neural mediators for particular behaviors sometimes change with age, experience, or the need for compensation; b) vulnerability may vary with the sex of the individual; and c) effects may only be detectable under more challenging conditions. Data illustrating these issues can be found in the background paper by Rice and Barone (18).
These issues have been recognized for years and now cumulative evidence demands increased attention to the age of assessment. The research issue to be resolved is whether testing in screening studies of young adult experimental animals alone is adequate to identify long-term consequences of developmental perturbations. We focus only on the issue of improved detectability under challenging conditions. There are five approaches that could reveal the subclinical long-term effects of developmental exposure, whereby detectability is revealed through a) aging-related functional or morphological loss, $b$ ) pharmacological challenge to the integrity of a particular neurochemical system, $c$ ) response to environmental stressors, $d$ ) increased task complexity, or $e$ ) histological examination of the brain that includes quantitative assessments at different life stages. Long-term consequences of chemical exposure during development could be examined in an adjunct way in screening studies evaluating exposure over the lifetime in multigeneration-reproductive screening studies.

Methyl mercury was the first compound to draw considerable attention to the phenomenon of developmental exposures manifesting effects revealed with aging $(18,74,75)$. Animal and human studies have identified motor and sensory deficits with increasing age that were not seen at earlier time points after the cessation of exposure as well as a worsening of conditions with age. By way of comparison to another agent, rats exposed to triethyltin during early postnatal development demonstrated decrements in cognitive performance at 24 months of age that were not seen at 3 months of age and at 1 year of age (70).

Pharmacological challenges have been widely used in animal studies to examine functioning in specific neurochemical systems [reviewed by Meyer (11)]. Such challenges serve as probes to evaluate the integrity of particular systems that are pharmacological targets of the developmental toxicant under study or that influence behaviors under study. Generally, agonists, antagonists, or agents that up-regulate or down-regulate the transmitter system are used. Historically, drug challenge studies have been commonly used to examine changes in actuvity, body temperature, tremor, forepaw treading, head weaving, or threshold for catalepsy. These studies by inference reflect changes in neural connectivity and neurotransmission.

Increased sensitivity to various environmental stressors has also been seen in animals exposed to developmental toxicants. For example, the review by $S$ pear et al. (77) showed that rats prenatally exposed to cocaine have increased sensitivity to stressors such as early manipulation, social competition, and immobilization.
Animal models of multiple human mental retardation disorders have demonstrated the difficulty of most assessments of learning in rats in capturing expected deficits, in part because of the simplicity of routinely used measures of learning and memory in rodents. Task complexity unmasks various learning deficits $(78,79)$. Cumulatıve learnıng tasks that require transfer of training experience appear particularly useful in revealing learning deficits. This has been demonstrated in multiple studies using operant schedules of increasing complexity to examine deficits in animals [reviewed by Rice and Barone (18) and Paule et al. (80)]. Examinations of the ability to shıft or reverse learning rules provide added detection sensitivity in nonoperant tasks such as versions of the water maze and other tasks $(19,81)$. Finally, learning methods that make demands on working memory, such as delayed alternation tasks [reviewed by Rice and Barone (18)] or other tasks that require timing or inhibition of responses [reviewed by Paule et al. (80)], appear to offer increased sensirivity. These types of functional assessments can be more sensitive to perturbation of the development of the nervous system than tasks that use only simple acquisition of spatial learning or onetrial learning tasks (e.g., active avoidance or passive avoidance tasks).

\section{Developmental Effects May Unfold throughout Life}

\section{Are There Critical Points That Determine the Course of Development That Can Lead to Differences in Vulnerabilities at Later Times?}

We have emphasized a sequence of developmental events that are interrelated, and we also emphasized that functional effects unfold throughout the lifespan. Certain effects become evident only as relevant functronal capacities emerge. Other effects manifest with declines in reserve capacities that become functionally expressed subsequent to aging or under more challenging test conditions. Because the brain and behavior are constantly influenced by experience, any alteration in the integrity of nervous system function at one point in time predisposes a risk to the ongoing and furure integrity of the structure and function of the nervous system. In this sense, cascades of effects are an unavoidable consequence of the prime directive of nervous system functioning: the continual adaptation to environmental change through constant processing of information and neural remodeling.

Because of the cascade of effects that exposure can have on development and function of the nervous system, sometimes there is debate regarding which behavioral effects are 
primary and which may be secondary consequences or downstream manifestations. For example, we may wish to determine if all children with comparably reduced intelligence have correspondingly reduced attention spans, or if a particular genetic disorder, disease, or agent appears to more selectuvely target neural substrates for attention. In a risk-assessment cnvironment, all detrimental effects collectively represent effects to be avolded. When cause-effect relationships need to be scientifically understood for several different behavioral outcomes, however, or when intervention may be used to mitigate a known cascade, it is useful to be able to tease primary and secondary effects apart. Prumary effects are manıfest on neural architecture or physiology but may be expressed most notably on altered hehavioral functioning. Certain behaviors are more proximal to the neural effect caused by exposure than others. For cxample, certan agents appear to alter attention span, impulsivity, or actuvity levels in children. As a subpopulatıon, chıldren with poor impulse control (for whom most etiologies are unknown) are at increased risk for poor academic performance and accidents, for the devclopment of substance abuse disorders, and cven for criminal activity [reviewed by Pennungton (82)]. These downstream outcomes have high societal costs and may occur with increased risks in children exposed to a variety of developmental roxicants (18). Knowledge of the relationship between the antccedent problems in impulse control and the increased risk for later manifestation of other sociobehavioral problems can be helpful in channeling children and therr families into intervention programs to try to reduce futuro correlared manifestations. It is difficult to fully parse the effects of toxic exposure on childhood impulsivity versus increased criminality because nonexposure-related variables might intervene to determine the progression from impulsivity to cruminality. If we wish to associate the effects of a developmental toxicant with a downstream manifestation of this type, we must design studies that attempt to further address the intervening variables of importance (educational characteristics and family and home characteristics). Research must not only compare exposed children to demographically matched nonexposed children but should also contrast the long-term behavioral characteristics of exposed children with those of children with similar ealy behavioral characteristıcs (like impulsivity) not due to exposure. This would allow decermining agent-specific versus more generic behavioral profiles present in all children with predisposing personal and familial risk factors.

In addition to the interrelated events that determune each stage of nervous system development and the funcrional cascades described above, it is important to recognize that developmental exposure to certan agents may also alter later physiological or neurochemical responses. For example, prenatal exposure to cocane $(66,83,84)$ alters later pharmacological sensitivity to dopaminergic agents as well as to ethanol (85).

\section{Information on Critical Windows May Suggest Susceptible Subgroups of Children}

Neurobehavioral characteristics of children are influenced by patental socioeconomic status, parental age, educational background, and ethnocity. These important variables must be controllcd through experimental design or statistical procedures whencver neurobehavioral outcomes are exammed. Further, infant characteristics such as sex, small-for-gestational-age status at birth, and the presence of birth complicatıons increase the risk for compromised motor or intellectual development. This presents a dilemma for associating early exposures with adverse neurobehavioral effects, particularly when the exposure reduces burth weight, increases prematurity, and/or complicates the burth process in other ways. At the screening level, we decm it fully acceptable for the entire cascade of events to be viewed as increased because of exposure and therefore believe that it represents effects that we would wish to avold for any environmental agent. However, it may also be important to determine if the full cascade of effects is prototypical in incidence and generic to any child born with comparably reduced birth weight, comparable prematurity, or a comparable experience of another birth complication. This determination can be answered only through studies with appropriate contrast groups as well as control groups.

\section{Gaps in Existing Data}

Previous discussion has emphasized the need for $a$ screenung-level assessment of cytoarchitectural aspects of neuroanatomy and molecular aspects of function, $b$ ) expanded knowledge of preembryonic exposure effects, nonmalformation outcomes after embryonic exposure, as well as effects consequent to exposures during adolescence, and () development, validation, and incorporation of more sensituve methods to assess learning and memory within a screenung context.

The issue of hazard characterization of anatomical effects after developmental exposure continues to be a problem of where and when to look for alterations. Histological examınation usıng both qualitative and quantitative examination during development and into adulthood can reveal adverse effects after developmental exposure during different critical periods $(58,76,86)$. Currently, screening approaches, including examination of representative structures of the brain that develop both prenatally and postnatally, are required under the U.S. F.PA testing guidelines for developmental neurotoxicity (14). This guideline was designed in the late 1980 s with apical measures in mind. As more data become available using this guideline and newer methods are developed, this guideline for screening chemicals for developmental neurotoxicity could and should evolve. A number of practical considerations and scienrific issues will probably influence the development of newer testing strategies. Furst, as an example of the practical issues, there are a large number of high production/volume chemicals (approximately 3,000) that have not been examined at all for developmental neurotoxicity $(87,88)$. This issue, among othcrs, suggests that alternative means of testing and/or prioritization of testing may need to be used. The Endocrine Disruptor Screening and Testing Advisory Committee is an example of this approach based on the development and evaluation of a battery of in vitro and $t n$ vivo tests with a scientifically sound mechanistıc basis. Currently, a number of in vitro tests are available for testung different processes critical to development of the nervous system such as proliferation, differentiation, and apoptosis; however, little coordination of resources has been devoted to the validation and application of such tests as adjuncts to a developmental neurotoxicity screening battery for testing chemical hazards. In addition to hazard identification and prelimmary screening, these tests could serve to provide some mechanistic underpinning for how a chemical or class of chemicals affects development of the nervous system. Developmental neuroscience has provided a rapid expansion of information about the genetic and epigenetic control of developmental processes. The use of both in nitro culture models derved from rodents and human stem cells and immortalized neurons derived from humans may facilitate comparisons of chemicals on the basis of effects on developmental processes critical to normal vertebrate brain development. Identifying the effects related to aggregate and cumulative exposures during development of the nervous system is complex; however, future research could examine these developmental processes both in vitro and $i n$ vivo with the goal of identifyIng the chemical's mode of action in a way that could be extrapolated across species.

Additionally, consideration of the chronic versus acute nature of potential human exposures and of relevant pharmacokınetic information should be utilized in the design of dosing schedules used in screening studies. 
Finally, there is a need for development of animal screening methods that evaluate social and emotional functioning and a need for incorporation of assessments of mental health functioning into human studies. Conversely, there is a need to determine the role of developmental insult in the etrology of human psychiatric disorders through research on these populations. The reconceptualization of schizophrenia as a neurodevelopmental disorder has occurred over the last decade because of epidemiological studies addressing prenatal and adolescent variables (89-94). Also, insights into the etiology of autism have been gained through evaluation of the consistency between symptomatology and the disruption of early embryogenesis (24).

\section{Examinations and Estimation of Exposure-Response Relationships}

It is important that laboratory studies mode real-world exposure characteristics as closely as possible. To this end, information about the phast: versus tonic nature of exposure and the corresponding pharmacokinetic characteristics of the agent musi be taken into account whenever possible as a means of strengthening the design of screening studies. When exposure characteristics provide an appropriate model of the human exposure scenario, responses to exposure can then be measured with all of the recommendations and caveats that have been a major focus of this paper

This posed question is more formidable in the context of human epidemiological studies. Outside of the laboratory environment, exposure assessment in epidemiological studies is challenging because these studies lack simplified quantification to iddress issues related to age-based vulnerabiltry and this assessment is often precluded by the large numbers of individuals necessary to permit breakdown into multiple age groups. Although power calculations can provide reasonable estimates of the numbers of people necessary to get reliable results, estimates are more accurate when preexisting data are available to identify the end point(s) of interest and the magnitude of the effect to be reasonably expected. When the effect is easy to measure or to quantify, this makes it simpler to use the minimum number of participants determined using the power calculations. Otherwise, larger sample sizes need to be used to attempt to find less readily detectable effects. Aside from difficulties inherent in satisfying sample size needs, however, there are greater complications associated with estimating exposure and measuring the outcome of interest. Although estimating exposure based on careful interview techniques along with determinations of local residual environmental contamination and residues in human tissues is possible but problematic, it has been more problematic to associate exposures with narrow developmental time periods. Nevertheless, this may be necessary to optimally estimate risks that are highly stage dependent. When the environmental or occupational contamination is confined to a particular time period, studies could attempt to parse the exposed participants into groups differing according to biologically meaningful periods of exposure. Provided that adequate sample sizes could be used, selection of groups according to ongoing developmental events at the time of exposure might improve the ability to address exposure-response events. In other words, detectabilıty might be optimized under conditions where the biological plausibility of the cause-effect relationship under study is maximized by narrowing the window of exposure to the most vulnerable stage of development. When groups include participants exposed outside of the period of greatest vulnerability for disruption of the end point of interest, the presence of these added participants could dilute the ability to detect the effect. Thus, a trade-off between sample size and sensitivity of the design is always present and must be carefully considered. This issue is of paramount importance in studies where major malformations are the end points of interest.

It is also critical that the outcome of interest be examined with attention to a number of potential moderating variables. It is important to design studies that address the interactive effects of variables that may affect the results, such as socioeconomic status, parental smoking, alcohol, or illicit drug use, as well as use of prescription or over-the-counter compounds. Human lead studies [reviewed by Dietrich et al. (38)] have paid a great deal of attention to these variables, as have some human studies of substances of abuse [reviewed by Rice and Barone (18) and Richardson and Day (95)].

Launching new large-scale, prospective, longitudinal studies of diverse groups of children and pregnant women would provide sound information from which the effects of various exposures on sensory, motor, cogn1tive, emotional, and mental health outcomes could be measured. Regular blood or tissue sampling from the participants could provide a database from which numerous questions could be asked about developmental exposures to specific agents. Such an ambitious undertaking, however, would be quite costly and lengthy. Nevertheless, the greatest benefit would be derived from a prospective comprehensive design.

The limitations of retrospective designs generally compromise the quality of the information obtained. Nevertheless, a very useful initial approach to addressing many questions about developmental toxicity involves the use of existıng databases. Many very large studies, such as the Collaborative Perinatal Project (96) (a prospective longitudinal study) and the National Health and Nutrition Examination Study (NHANES) (90) (a cross-sectional study), have been conducted. NHANES periodically surveys a sample of the U.S. population to assess a large number of health parameters and biological measures. Thus, a database of questionnaire responses and a large collection of stored serum, urine, and other specimens exist for this population. NHANES IV is currently in the data collection phase, and should provide the greatest range to date of specimens from the entire U.S. population. These stored banks of biological specimens could serve as valuable resources for investigators who are not able to launch a completely new study. With respect to behavioral outcomes, however, they are somewhat limited and would no doubt demand additional data collection. Of particular value to neurodevelopmental toxicity studies are Scandinavian databases $(90)$ that contain extensive health records, extensive educational records, and scores on measures of intellectual functioning.

\section{Other Exposures May Interact with Exposures of Concern}

In human populations, the prevalence of caffeine, cigarette, and alcohol use complicate the study of specific toxic agents in the environment. Similarly, diets of varyıng nutritional quality and the use of commonly prescribed psychoactive drugs or hormones may interact with the assessment of risks of exposure to environmental agents. Therefore, it is important to determine the usage of common substances when human experimental or epidemiological studies are done. In studies of developmental neurotoxicity, the influence of many of these variables on the effects of nonelective exposures has been addressed through statistical means: Information is generally obtained via questionnaire and used as a covariate. Excellent examples and descriptions of these approaches can be found in reviews by Bellinger and Dietrich (37), Dietrich et al. (38), Richardson and Day (95), and Fried and Makin (97).

\section{Laboratory Animal Data Predict Human Responses}

Many conferences, symposia, and individual publications have addressed the issues surrounding the predictive value of rat and primate studies to humans. Of particular interest has been how well animal behavioral data 
predict human behavioral responses. Efforts to address this question have generally chosen specific agents and categories of end points, then looked for concordance in the demonstration of effects within each category. When focusing on the extrapolation of animal behavioral data, evaluations have been made of the effects of specific neurotoxicants on functional categories such as general developmental landmarks, sensory, motor, learning and memory, and social behavior $(98,99)$. This approach suggests that reliable and valid animal data predict human responses very well. For example, agents that disrupe sensory-evoked potentials and other electrophysiological parameters in humans produce similar disruptions in rats and primates $(18,100)$. Further, behavioral dysfunctions tend to depend on similar neural substrates across species. Thus, the specific behavior disrupted in one species can be linked to alterations in particular neurobiological substrates that also mediate a similar category of behavior in humans $(18,21)$.

Nevertheless, within the context of methods used in screening batteries, extrapolation appears strongest with regard to effects on sensory and motor functioning, and is somewhat less strong for cognitive or social functioning. We emphasized the need to further challenge the integrity of learning mechanisms through task complexity as a means of improving screening-level detection of deficits in learning and memory. Whereas models of social behaviors such as infant suckling, maternal-infant interactions, or reproductive behavior appear to produce concordant effects across species, more complex aspects of human social behavior have not been modeled in animal studies of developmental toxicity. Likewise, approaches to assessing animal behavioral end points that adequately screen for potential effects on emotional or mental health end points have not been broadly applied. As the neurobiological understanding of mental health disorders has expanded, it has become clear that altered brain development may predispose individuals to increased vulnerability to stress and mental health disorders $(89,90)$. More attention to this research issue is needed in both animal and human developmental toxicity studies.

\section{Implications for Risk Assessment and Public Health}

We emphasized certain shortcomings of current screening approaches and epidemiological studies, certan methodologies that appear to be more sensitive in identification of developmental neurotoxicity, and the need for improved understanding of toxicity during certain vulnerable periods or on certain end points. Some of our discussion can be translated into immediate actions, whereas other points emphasize longer term goals that demand more research and data before application. Explicitly, we suggest the following:

- In rodent screening studies, when background data are not available on the agent, allow a broad exposure window from fertilization through adolescence for agents that would have an extended exposure period in humans.

- Use pharmacokinetic data and human exposure characteristics to determine the logical window of exposure for use during screenıng studies aimed at risk assessment.

- When plausible and logical given the realworld exposure situation, interweave morphological and functional testing into multigenerational studies to cover the full spectrum of development (i.e., womb to tomb).

- Derermine the nature of developmental neurotoxicity following exposures before the induction of the neural plate and during the adolescent period.

- Use more contemporary and sensitive methodologies for evaluating behavior when the methodologies are amenable to the screening context-add prepulse inhibitıon to the startle paradigm, improve water maze learning tasks by the addition of reversal learning, and examine morphological and functional effects in young as well as aged animals.

- Develop measures of cumulative learning that are amenable to the screenıng context and determine if these are more sensitive than the basic learning tasks currently used.

- Increase the use of neuropathological assessments to cover the broader spectrum of development of the brain. This could be performed in screening studies with the examination of the brain in both teratology and multigenerational study protocols. It could also complement other work performed in developmental neurotoxicity screening studies.

- Develop screening techniques that examine cytoarchitectural and molecular aspects of nervous system functioning.

- Examine the relationship between sensitive measures of neuroanatomy, molecular functioning, and behavioral compromise (with the long-term goal of a viable tiered approach to the selection of agents for behavioral evaluation based on altered neural structure or molecular characteristics).

- Use biological plausibility for causation of the outcome of interest to narrow the developmental periods now examined in epidemiological studies.

- Perform preliminary examinatıons of developmental neurotoxicity in humans and seek concurrent validation of results through the examination of data derived from larger samples available in existing databases.

- Initiate human prospective and longitudinal studies that collect tissue samples as well as neuropsychological data.

\section{References and Notes}

1 Wison JG Environment and Birth Defects New York Academic Press, 1973

2 Schaefer GB, Bodenstenter JB Evaluatıon of the child with idiopathıc mental retardation Pediatr Clin North Am 39 929-943 (1992)

3 K.mmel CA, Buelke-Sam J Developmental Toxicology New York Raven Press, 1981

4 Slikker WJ, Chang LW Handbook of Developmental Neurotoxıcology San Diego Academic Press, 1998

5 Riley EP, Vorhees CV Handbook of Behavioral Teratology New York Plenum Press, 1986

6 Adams $\mathrm{J}$ Structure-activity and dose-response relationships in the neural and behavioral teratogenesis of retmoids Neurotoxico! Teratol 15 193-202 (1993)

7 Adams J. Holson RR The neurobehavioral teratology of Vitamın A analogs In Handbook of Developmental Neurotoxicology iSlikker WJ, Chang [W. eds) San Drego Academic Press, $998,631-642$

8 Freeman JHJ, Barone SJ, Stanton ME Cognitive and neuroanatomical effects of tulethyltin in developing rats role of age of exposure Brain Res 634 85-95(1994)

9 Barone SJ Developmental differences in neural damage following trimethyl-tin as demonstrated with GFAP immunohistochemstry Ann NY Acad Scl 679 306-316 [1993]

10 Freeman JHJ, Barone SJ, Stanton ME Triethyltın produces neural damage and cognitive deficits in developing rats that depend on age of exposure Brain Res 634 85-95 \{1994]

11 Mever JS Behavioral assessment in developmentai neurotoxlcology approaches involving unconditioned behaviors and pharmacologic challenges in rodents in Handbook of Developmental Neurotoxıcologv (Slikker WJ. Chang LW. eds) San Diego Academic Press, 1998,403-426

12 Kımmel CA Current approaches to risk assessment for developmental neurotoxicology In Handbook of Developmental Neurotoxicology (Slikker W., Chang (W. eds) San Diego Academic Press, 1998,675-686

13 Adams J Methods in behavioral teratology In Handbook of Behaviral Teratology (Rıley EP, Vorhees CV, eds) New York Plenum Press, 1986,67

14 U S EPA Health Effects Test Guidelınes OPPTS 8706300 Develapmental Neurotoxicity Study Washıngton, DC U S Environmental Protection Agency, 1996

15 Vorhees CV Origins of behavioral teratology In Handbook of Behavioral Teratology (Riley EP. Vorhees CV edsl New York Plenum Press, 1986, 3-22

16 Vorhees $C V$ Principles of behavoral teratology in Handbook of Behavioral Teratology (R॥ley EP, Vorhees CV, eds) New York Plenum Press, 1986, 23-48

17 Buznıkov GA, Shmukler Y, Lauder JM Changes in the physiological roles of neurotransmitters during individual development Neuroscl Behav Physiol 29 11-21 (1999)

18 Rice DC, Barone SJ Critical periods of vuinerability for the developing nervous system evidence from humans and antmal models Environ Health Perspect 108 511-533 (2000)

19 Vorhees CV Reliability, sensitivity and validity of behavioral indices of neurotoxicity Neurotoxicol Teratol 9 445-464 (1987)

20 Kimmel CA, Buelke-Sam J Collaborative Behaviorai Teratology Study background and overview Neurobehav Toxicol Teratol $7541-545(1985)$

21 Holson RR When is a rat a boy? In Organ System Maturation and Functional Postnatal Development Aspects to Consider for Pediatric Safety Assessment (Tassinarı M, ed) Bethesda. MD Teratology Society, 1999, D1-D42

22 Jensen KF, Catalano SM Brain morphogenesis and developmental neurotoxicology In Handbook of Developmental Neurotoxicology (Slkkker WJ. Chang LW, eds) San Diego Academıc Press, 1998,3-42

23 Bennett GD, Finnell GD Periods of susceptibility to induced malformations of the developing mammalian brair in Handbook of Developmental Neurotoxicology (Slikker WJ Chang LW. eds) San Diego Academic Press. 1998, 189-208 
2. Rodier PM Neuroteratology af autism In Handbook of Develoomer tal Neurotoxicology (Slikker WJ, Chang LW, eds) San Diego Academic Press, 1998,661-672

$2^{1 / 3}$ Rodier PM, Ingram JL TIsdale B, Nelson S, Romano J Embryologic al origen for autism developmental anomaties of the cranal nerve motor nuclea $J$ Comp Neurol 370 247-261 $(1996)$

'ij Hoison RR, Gazzara FA, Ferguson SA, All SF, Laborde JB. Adams $J$ Gestational retinoic acid exposure a sensitive period for eftects un neonatal mortality and cerebeliar development Neurotoxiccl Teratol 19 335-346 (1997)

7 Holson RR, Gazzara RA. Ferguson SA, Adams J Behavioral effects of lisw-dose gestational day $11-13$ retinic acid expo sure Neurotoxicol Teratol 19 355-352 \{1997)

B Holson RR, Gazzara RA. Fercuson SA. Adams J A behavioral and neurcanatomical investigation of the lethality caused by gestationaı day 11-13 retinjic acid exposure Neurotoxicol Teratol $19: 47-353$ (1997)

9 Lammer EJ. Chen DT Hoar RM. Agnish ND. Benke PJ Braun JT, Curry CJ, Fernhoff PM, Grix. AW Jr, Lott IT Retınołc acid embryopatt y N Engl J Med 313 837-841 (1985)

- Danski, LV, Finnell RH Parental eplepsy, anticurivulsant drugs, and reprocuctive outcome epidemiologic and experimenta findings sfanning three decades ? Human studies Reprod Toxicol $53[11-335: 1991$

'1 Fonnell BH, Dansky LV Parental epllepsy, anticarvulsant drugs and reprocuctive outcome epidemiologic and experimental findings spranning three derades 1 Animal studies Reprod Toxiccl 5281 -.-299 (1991)

32 Hansen OK, Holson RR Developmental reurotoxicology of antieprleptic drugs in Handbook of Developmental Neuratox cology (Slıkke- WJ. Chang LW. eds\} San Diego Acarlemic Press, 1998,543-660

33 Kemperma n G, Gage FH New nerve cells for the adult bran Sol Am 28( 48-53 (1999)

34 Barore S. Applicatıons o* the neurotrophic hypothesis to developmintal neurotoxicrlogy In Target OIgan Toxicry Neurotoxicology (TIIson HA. Harry GJ. edsi Washington. DC Taylor \&\& Francis, 1999.179-200

35 Barone SJ, Das KD, Laseiter TL White LD Vulnerable processes of nervous syster development a rewew of markers and methots Neurotoxicology 2111-2) 15-36 (1999)

36 Dietrich K Environmental tcxicants and child development In Neurodevelopmental Disisders Contributions to a New Framework from the Cognit ve Neurosclences ITager-Flusberg H, ed' Caribridge MAMIT Press, 1999,469-49C

37 Bellnger 0, Dietrich KN Low level lead exposure and cognitive function in children Pediatr Amn 23111) 600-605 (1994)

38 Dietrich KV Berger DG, Succop PA, Hammonc PB. Bornsheın RL The developmental consequences of low to moderate prenatal and postriatal lead erposure intellectual attanment in the Cincinnatı Lead Study: Cohort following school entry Neurotoxit ol Terato $15(1) 3,-44$ (1993)

39 Rice DC Behavoral effects of lead r.ammonalities between experimer tal and epidemioiogic data Environ Health Perspect 104|supp| 2) 337-351 (1996)

40 Rice DC [levelopmental lead exposure neurobehavioral consequences In Handtook of Developmental Neuroloxicology [Slikker WJ, Chang [W, eds] San Diego Arademic Press, $1998539-557$

41 Dietrich KN, Succop PA, Bornschein RL, Krafft KM. Berger 0. Hammond PQ, Buncher CR Lead exposure and neurobehaviora deveropment in later infancy Environ Health Pespect 89 13-19 1990)

42 Averill D. Needleman $H$ Neonatal lead exposure retards cortical synaptogenesis in the rat In Low Level Lead Exposure The Clinıcal Iroplıcatıons of Current Research (Neidleman H. ed) New York Raven Press, 1980,210-219

43 McCaule\} PT. Bull RJ. Tontı AP. Lutkenhof SD, Messter MV Doerger IL, Stober JA The effect of prenatal and postnatal lead exposure on neonatal synaptogenesis in lat cerebral cortex J Toxicol Environ Health 10 639-651 (1982)

44 Hoff SF Syraptogenesis in the hippocampal dentate gyrus effects of in utero ethariol exposure Brain Res Bull $2147-54$ (1988)

45 Kawamoto JC, Overmann SR, Woolley DE, Vijayan VK Morphometric effects of preweanıng lead expcsure on the hippocampal formation of adult rats Neurotoxicologv 5 125-148 (1984)

46 Audesirk G, Audesirk T Neurite development In Handbook of Developmental Neurotoxicology (Slikker WJ, Lhang LW. eds) San Diegu Academic Press, 1998,61-86

47 Gilbert ME, Mack CM. Lasley SM The influence of develop mental period of lead exposure on long-term potentiation in the adult rat dentate gyrus in vivo Neurotoxicologv 20 57-69 (1999)

48 Johnston MV, Goldstein GW Selective vulnerability of the developing brain to lead Curr Opın Neurol 11/6) 689-693 (1998)

49 Cookman GR, King W. Regan CM Chronic low level lead exposure impairs embryonic to adult conversion of the neural cell adhesion molecule $J$ Neurochem $49(2 \mid 399-403$ (1387)

50 Harry GJ, Toews AD, Krigman MR, Morell P The effect of lead toxicity and $m \mid k$ deprivation of myelınation in ther rat Toxicol Appl Pharmacol 77 458-464 (1985)

51 Harry G.J. Toews AD Myelination, dysmyelınation, and demyelınation In Handbook of Developmental Neurotoxicology (Slikke WJ, Chang LW. eds) San Diego Acadernic Press, 1998,87-116

52 Cookman GR. Hemmens SE, Keane GJ, King WB, Regan CM Chronc low level lead exposure precociously indices rat glial development in vitro and in vivo Neurosci Lett 86(1) 33-37 $(1988)$

53 Lasley SM. Green MC, Glbert ME Infiuence of exposure period on in vivo hippocampal glutamate and GABA release in rats chronically exposed to lead Neurotoxicology 20 619-630 (1999)

54 Gullarte TR The N-Methyl-D-aspartate receptor plysılogy and neurotoxicology in the developing brain in Handbook of Developmental Neurotoxicology (Slikker WJ, Chang LW, eds) San Diego Academic Press, 1998,285-304

55 Chang LW. Reutil KR, Lee GW Degenerative changes in the developing nervous system as a result of in utero exposure to methylmercury Environ Res 14 414-423 (1977)

56 Burbacher TM. Rodier PM, Weiss B Methylmerrury develop mental neurotoxicity a comparison of effects in humans and anımals Neurotoxicol Teratol 12 191-20211990)

57 Chang LW Guo TL Fetal Minamata Disease In Handbook of Developmental Neurotoxıcolgy (Slıkker WJ, Chang LW eds) San Diego Academic Press, 998,507-516

58 Barone S J. Haykal-Coates N. Parran DK. TIlson HA Gestatıonal exposure to methylmercury alters the developmental pattern of trk-like immunoreactivity in the rat brain and results in cortical dysmorphology Dev Brain Res 109 13-31 (1998)

59 Haykal-Coates N. Shafer TJ, Mundy WR, Barone S Jr Effects of gestational methyimercury exposure on immunoredctivity of specific isoforms of PKC and enzyme activity during post-natal development of the rat brain Dev Brain Res 109 33-49 (1998)

60 Mundy WR, Parran DK, Barone S Jr Gestational exposure to methylmercury alters the developmental pattern of neucotrophın- and neurotransmitter-induced phosphoinositide (PH) hydrolysis Neurctoxicol Res (in press)

61 Jernigan TL. Trauner DA, Hesseiınk JR, Tallal PA Maturation of human cerebrum observed in vivo durng adolescence Bran $114(\mathrm{Pt}$ 5) 2037-2049 (1991)

62 van Eden CG, Kros JM, Uylings HBM The development of the rat prefrontal cortex its size and development of connections with thalamus, spinal cord and other cortical areas in Vol 85 The Prefrontal Cortex its Structure. Function, and Pathology UVylings HBM, van Eden CG, DeBrun JPC, Corner MA, Feenstra MGP, eds) Amsterdam Elsevier, 1999, 169-183

63 Zecevic N. Rakıc P Synaptogeness in monkey somatosensory cortex Cereb Cortex 1510-523 (1991)

64 LewIS DA Development of the prefrontal cortex during adolescence insights into vulnerable neural crrcuits in schizophrenia Neuropsychopharmacology 16 385-398 (1997)

65 Andersen SL, Dumont NL, Teicher MH Developmental differ ences in dopamine synthesis inhibition by i-1-7-OH-OPA Naunyn-Schmerdelberg's Arch Pharmacol 356 173-181 19997)

66 Tercher MH. Barber NI, Gelbard HA, Gallıtano AL, Campbell A. Marsh E. Baldessarını RJ Developmental differences in acute nicrostriatal and mesocorticolımbic system response to haloperidol Neuropsychopharmacology 9 147-156 (1993)

67 Benes FM Myelination of cortical-hippocampal relays during late adolescence Schizophr Bull 15 585-593 (1989)

68 Dumas TC. Foster TC Late develoomental changes in the ability of adenosine $A 1$ receptors to regulate synaptic transmission in the hippocampus Dev Brain Res 105 137-139 (1998)

69 Chor S, Weisberg SN, Kellogg CK Control of endogenous noreplnephrine release in the hypothalamus of male rats changes over adolescent development Dev Brain Res 98 134-141 (1997)

70 Salımov RM, McBride WJ, McKınzıe DL, Lumeng L, LI TK Effects of ethanol consumption by adolescent alcohol-preferring $P$ rats on subsequent behavioral performance in the cross-maze and ship funnel tests Alcohol $13297-300$ (1996)

71 Goliszek AG. Crawford GE, Lawrence HS. Bennett d, Willams F. Hurley SL Effects of prepubertal stress on suksequent ACTH response to novel stress and $\mathrm{CRH}$ in male vs female rats Stress Med 12 199-204 (1996)
72 Spear (P The adolescent brain and age-related behavioral manifestations Neurosci Behav Rev (In press)

73 Spear LP Neurobehavioral changes in adolescence Curr Dir Psychol Sci (in press)

74 Rice DC Age-reiated increase in auditory imparment in monkeys exposed in utero plus postnatally to methylmercury Toxicol Sc 44 191-196 (1998)

75 Rice DC. Hayward S Comparison of visual furction at adulthood and during aging in monkeys exposed to lead or methylmercury Neurotoxicology 20(5) 767-784 (1999)

76 Barone SJ, Stanton ME, Mundy WR Neurotoxic effects of neonatal triethyltin (TET) exposure are exacerbated with aging Neuroblol Aging 16 723-735 (1995)

77 Spear L.P. Campbell J. Snyder K. Silverı M. Katovic N Anımal behavior models increased sensitivity to stressors and othe environmental experiences after prenatal cocaine exposure Ann NY Acad Sol 846 76-88(1998)

78 Strupp B.J, Himmelstein S. Bunsey M, Levitsky DA, Kesier M Cognitive profile of rats exposed to lactational hyperphenylalaninemia correspondence with human mental retardation Dev Psychobıl 23 195-214 11990

79 Strupp BJ, Bunsey M, Levitsky DA, Hamberger K. Deficient cumulative learning an anımal model of retarded cognitive development Neurotoxicol Teratol 16 71-79 (1994)

80 Paule MG, Meck WH, McMillan DE, McClure GY, Bateson M Popke EJ, Chelonıs JJ, Hinton SC The use of tıming behaviors If, anımals and humans to detect drug and/or toxicant effects Neurotoxicol Teratol 21 491-502 (1999)

81 Vorhees CV Fetal anticonvulsant syndrome in rats dose-and period-response relationships of prenatal diphenyihydantom, trimethadione, and phenobarbital exposure on the structura and functional development of the offspring $J$ Pharmacol Exp Ther 227 274-287 (1983)

82 Pennington BF Attention deficıt hyperactivity disorder In Diagnosing Learnıng Disorders (Pennington BF. ed New York Gulford Press, 1991,82-110

83 Henderson MG, McConnaughey MM, McMillen BA Long-term consequences of prenatal exposure to cocane or related drugs effects on rat brain monoaminergic receptors Brain Res Bul $26941-945(1991)$

84 Moody CA. Frambes NA. Spear LP Psychopharmacological responsiveness to the dopamine agonist quinpirole in norma weanlings and in weanling offspring exposed gestationally to cocane Psychopharmacol Ser (Berl) 108 256-262 (1992)

85 Kelley BM. Groseclose CH, Mrddaugh LD Prenatal cocaine exposure increases the reinforcing strength of oral ethanot in C57 mice Neurotoxicol Teratol $19391-398$ (1997)

86 Freeman JHJ, Barone SJ. Stanton ME Disruption of cerebellar maturation by an antimitotic agent impairs the ontogeny of eye blink conditioning in rats $J$ Neurosci $157301-7314$ (1995)

87 Darr J Rankıng and Screenıng Risks in the OPPT Exıstıng Chemicals Program Avallable http / $/$ www epa gov/opptintr/ cre/ranking hłm [cited 6 April 2000]

88 United Nations. Environmental Programme Screening Information Data Set Avarlable http //Irptc unep ch/irptc/sids/ sidspub hitml [cited 18 Aprol 2000]

89 Susser E, Brown A, Gorman J Prenatal Exposures in Schizophirenia Washington, DC American Psychatric Press, (1999)

go Susser EB, Brown A. Matte TD Prenatal factors and adult mentai and physical health Can J Psychiatry 44 326-334 (1999)

91 Hoek HW. Brown AS. Susser E The Dutch famine and schizo phrenıa spectrum disorders Soc Psychiatry Psychiatr Epidemıol $33373-379(1998)$

92 Selten JP, Brown AS, Moons KG. Slaets JP, Susser ES, Kahn RS Prenatal exposure to the 1957 influenza pandemic and nonaffective psychos is in The Netherlands Schizophr Res 38 85-91 (1999)

93 Keshavan MS. Hogarty GE Braın maturatıonal processes and delayed onset in schizophrenia Dev Psychopathol 11 525-543 (1999)

94 LaMantia AS Forebrain induction, retınoic acid, and vulnerability to schizophrenia insights from molecular and genetic analy sis in developing mice Biol Psychiatry 46 19-30 (1999)

95 Richardson GA Day NL Epıdemologic studies of the effects of prenatal cocalne exposure on child development and behavior In Handbook of Developmental Neurotoxicology (Slıkker WJ, Chang LW, eds) San Diego Academic Press, 1998 487-496

96 Hardy JF, Drage JS, Jackson EC The First Year of Life The Collaborative Perinatal Project on the Natronal Instıtute of Neurological and Communicative Disorders and Stroke Baltımore The Johns Hopkns University Press, 1979

97 Fried PA. MakIn JE Neonatal behavioural correlates of prenata 
exposure to marihuana, cigarettes and alcohol in a low risk population Neuratoxicol Teratol 9 1-7 (1987)

98 Stanton ME, Spear LP Workshop on the qualitative and quanttative comparability of human and anımal developmental neurotoxıcity, Work Group I report comparabılity of measures of developmental neurotoxicıty in humans and laboratcry anımals Neurotoxıco! Teratol 12 261-267 (1990)

99 Buelke-Sam J. Mactutus CF Workshop on the qualitative and quantitative comparability of human and anumal developmental neurotoxicity. Work Group II report sesting methods in develop- mental neurotoxicıty for use in human risk assessment Neurotoxicol Teratol 12 269-274 (1990)

100 Davis JM, Otto DA, Well DE, Grant LD The comparative developmental neurotoxicity of lead in humans and anımals Neurotoxicol Teratol $12215-229$ (1990) 